\title{
Measuring defence
}

\section{SUMMARY}

This article describes current methods for measuring defence in the UK National

Accounts, based on staff numbers and other inputs. It sets out proposals for improvements to these measures, making better use of information on the composition of military staffing and spending. It also discusses some innovative proposals for the direct measurement of defence output. One such measure could be based on activities, for example, the proportion of Armed Forces personnel engaged in military operations or training. Another measure could be of 'capabilities' based on the quality and readiness for use of personnel and equipment. $\checkmark$ ntil 1998, the conventional approach to measuring government output in the National Accounts involved using the volume of inputs as a proxy for output (otherwise known as the output = input convention). This approach means that change in productivity is zero over time because measured inputs will always be equal to output. Under the International System of National Accounts (SNA), it was agreed that government output should instead be measured through direct measures of the volume of output. This allows the possibility of comparing inputs and output to measure change in productivity.

Since the late 1990s, the Office for National Statistics (ONS) has adopted direct measures of output for some public services, with significant progress being made for services such as health, education and social security administration. However, defence is still measured using the output $=$ input convention. This satisfies international standards, as defence is a collective service, that is, it is provided simultaneously to the whole society rather than to individuals.

This article summarises proposals raised in a separate article (Anagboso and Spence 2008). It discusses improvements that could be made to the existing measures of defence inputs in the National Accounts and sets out proposals for the direct measurement of defence output. Output measures being proposed in this article will not be considered for National Accounts.

Developmental work on the measurement of defence inputs and output has been undertaken as part of ONS's commitment to continuously improve the methods it applies in the production of National Statistics.

\section{Defence in the National Accounts}

Defence activities can be broadly described as the administration, supervision and operation of military affairs and land, sea, air and space defence forces. In the National Accounts, defence is split into two categories: military defence, and other defence, with the latter making up around 0.1 per cent of defence spending. Other defence includes: civil defence, foreign military aid, defence research and development and defence not elsewhere classified.

The Ministry of Defence (MoD) is responsible for the Armed Forces, including the operation of military academies, the provision of services to military veterans and the provision of accommodation to military personnel. It works to support the Government's foreign policy objectives, particularly those relating to peace and security, and is the lead department in the government's policy of defence diplomacy through the North Atlantic Treaty Organisation (NATO), Western European Union and the United Nations. It also fulfils the administrative tasks of a department of state including answering parliamentary questions.

In 2007, current price expenditure on

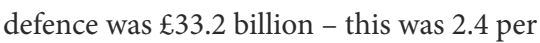


cent of GDP and 11.2 per cent of general government final consumption expenditure (GGFCE). Defence is the third largest government category as a proportion of total GGFCE spend, following health and education at 33.2 and 17.8 per cent of GGFCE, respectively.

\section{Measuring defence inputs}

An input is the collective term that defines all resources used to produce the output. Expenditure on inputs is broadly grouped into three categories: labour, goods and services, and capital.

Figure 1 shows the breakdown of defence current price expenditure between labour, goods and services, and capital consumption over time. The average proportions between 1996 and 2007 were: $56.8,37.5$ and 5.7 per cent for goods and services, labour, and capital, respectively. In 2007 , the MoD spent $£ 19.7$ billion on goods and services, $£ 11.8$ billion on labour and $£ 1.7$ billion on capital consumption.

A volume measure of inputs is needed for comparison over time and for productivity analysis, since it removes the effects of inflation. There are two approaches to measuring the volume of inputs: direct and indirect.

A direct method uses the number of units of a certain input, ideally with disaggregation by different levels of quality.

An indirect method uses the deflated expenditure on a given input. Deflation removes the effects of pay or price change from a current price expenditure series, so the remaining change in expenditure is due to changes in the volume of inputs only.

If the data used to construct these measures were perfect, then the direct and indirect measure would give the same result. However, as this is rarely the case, it is necessary to make a judgement as to which method gives the more accurate estimate.

\section{Defence labour}

The labour component of input measures the number, type and effort of staff used in the production process, for example, administrative staff, marines, pilots and soldiers. The MoD employs around 200,000 military personnel and 100,000 civilians, making it one of the UK's largest employers.

\section{Direct estimates of the volume of labour}

A direct estimate of the volume of labour should be based on numbers of staff employed, adjusted for hours worked and also for grade, military rank or skill level. Precision in measuring the changing skill mix of the workforce is important: an increase in the number of administrative staff would have a different impact on defence output than an increase in the number of fully trained Special Forces personnel.

\section{Indirect estimates of the volume of labour}

An indirect estimate of the volume of labour is obtained by deflating current price expenditure on labour by specific pay indices. An ideal pay index is specific to the workforce concerned, and is sensitive to any variations in pay rises for different types of staff, for example, taking a weighted average of the pay rise of administrative staff and Special Force staff, rather than just a simple figure based on (for example) the starting pay of a single type of staff.

The Eurostat Productivity Manual (Eurostat 2001) advocates a direct estimate of the volume of labour inputs, if appropriate data are available, because pay indices may

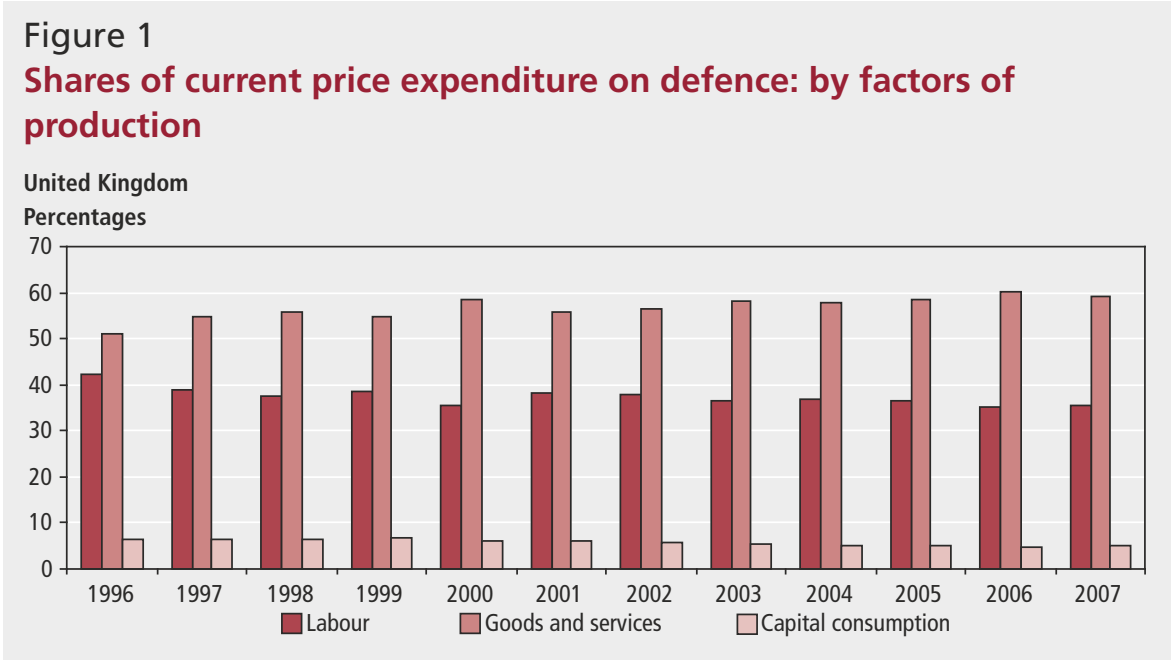

Source: Office for National Statistic not be sufficiently relevant and reliable. In practice, the requirements for ideal direct and indirect estimates of the volume of labour require similar levels of disaggregated data. The choice of method depends on whether a measure of change in hours worked by different staff types, or change in their pay, is more specific and accurate.

\section{Labour component of National} Accounts - defence figures

The current National Accounts method is a direct estimate of the volume of labour, based on the number of full-time equivalent (FTE) staff (civilian and military) working on military defence activities, multiplied by the average wage across the entire military defence workforce in the year 2000. This is shown formally in the Appendix.

The current measure has two key flaws:

- the number of FTE staff is counted but no account is taken of skill. Measuring workers' skill is crucial to the measure of inputs since, all other things being equal, skilled workers contribute more to production than their less skilled counterparts do, and a shift in the relative proportions of skilled and unskilled workers could be expected to affect output, and

- using weights fixed to the year 2000 means that the weights will not reflect changes in pay

Data available from Defence Analytical Services and Advice (DASA), the MoD and ONS can be used to improve the current measure.

- The direct measure could be improved by disaggregating the number of FTE staff. Staff numbers can be broken down into service personnel by rank, and civilian personnel by grade, weighted by wage

- An indirect measure could be developed using the expenditure on staff, split into service and civilian personnel, broken down by rank/grade and then deflated using rank/grade specific pay indices. Pay indices are available by rank, for service personnel, but not by grade for civilians. In this case, civilian expenditure would have to be deflated using pay indices for the public sector

Subject to further assessment, the direct labour method is likely to be more accurate, based on relevance and specificity of available data. 


\section{Defence-specific labour issues}

There are two particular issues for further consideration.

- Reserves - there are two types of reserves: regulars and volunteers. Regulars are people who have a liability by virtue of their former service in the regular forces; volunteers are those who have joined from the civilian community. Reservists are paid for training, and are paid if mobilised, and their employers are remunerated for any expenses incurred as a result of mobilisation. There is no doubt they should be included in the labour input measure as they work to produce defence, but consideration is needed, for a direct method, of how to weight their contribution relative to that of FTE active personnel. If an indirect measure is used, consideration is needed on the treatment of nonwage payments, such as payments to employers to cover the costs of recruiting temporary replacements

- Special allowances - when deployed, service personnel are given either or both of two allowances: operations allowance and longer-separation allowance. Operations allowances are paid when personnel are deployed in theatre, for example, Iraq and Afghanistan. Longer-separation allowances on the other hand are for separation and get paid irrespective of whether or not the service personnel are in theatre. These allowances can be described as compensation to them for being away from their families and, where applicable, the danger of being in combat. In a direct measure, these payments raise the question of whether time on active deployment should be weighted more highly than time spent training and other periods of duty

\section{Goods and services}

Goods and services are resources consumed during the production process. Examples of goods and services procured by the MoD are facilities management from external companies; fuel for planes, ships and tanks; and uniforms for military personnel. As with labour, the volume of goods and services can be estimated either directly or indirectly.

\section{Defence goods and services in the National Accounts}

The volume of military defence goods and services in National Accounts is measured indirectly by deflating total military defence expenditure on goods and services by a weighted deflator. The weighted deflator is calculated using the proportion of spending by the government in the year 2000 on certain sections of the economy, and their corresponding deflators. This is shown formally in the Appendix.

There are a number of problems with the current measure:

- using weights fixed to the year 2000 means that the deflator will not change to reflect the spending patterns in the given year

- the weights are based on the spending in the public administration and defence category, but would be more accurate if they were based on defence alone. Ideally, the deflators should be specific to prices paid by the MoD for goods and services

Data from DASA, the MoD and ONS can be used to improve the current measure. The indirect measure could be improved by disaggregating the expenditure into groups, according to the Standard Industrial Classification, and deflating using the producer price indices for these groups.

\section{Defence specific goods and services} issues

There is a further significant issue with the current goods and services measure in that it includes expenditure on destructive military weapons designed for combat (see Box 1). This means that the whole value of a relatively durable product (for example, a fighter jet) is included in the National Accounts in the year of purchase, rather than spreading the value of owning it over a period of years, as would be done if the products were treated as capital assets. This treatment is likely to make the time series for volume of goods and services more volatile than is really appropriate.

The current approach to the measurement of destructive military weapons is in line with the European SNA and SNA guidance. However, guidance on the measurement of durable military assets is likely to change under SNA 2008 such that durable destructive military assets should be capitalised as fixed assets rather than treated as goods and services. These changes are expected to be implemented in the National Accounts in the future and the UK Centre for the Measurement of Government Activity (UKCeMGA) intends to ascertain how this may affect the defence measures prior to their adoption in National Accounts.

\section{Capital}

Capital inputs to production are defined as either the consumption of capital (wealth), or the flow of services (production) from the available stock of capital assets of various vintages (Kimbugwe 2008). These two alternative measures of capital inputs are further discussed below.

Capital consumption is measured as the net reduction in the value of assets in a year, based on data on the value of the stock of assets, estimates of their remaining life, and the rate of depreciation.

Capital services measure the flow of productive services from an asset. For example, the productive services from a military building are the protection from the elements, and the comfort and storage capacity that the building provides each period. To calculate the volume index of capital services, a measure of the productive stock (capital stocks) and an estimated rental price is required. Estimates of capital

Box 1

\section{Current treatment of military durable goods in the National} Accounts

The 1993 SNA draws a distinction between two types of durable goods used by the military.

- Those 'that are used in much the same way as in any other type of production' - durable goods including airfields, docks, or other facilities used as bases, can potentially be used for civilian purposes, and are treated as fixed assets
- '....Destructive military weapons designed for combat' - rockets, missiles and their warheads and, by extension, missile silos, warships, submarines, fighter aircraft and bombers, and tanks are considered destructive, and are not treated as fixed assets. They are treated as intermediate consumption (goods and services) by general government

Source: UNstats (2003) 
stocks are taken from the ONS perpetual inventory model (PIM) while the estimated rental can be modelled from data on the rate of depreciation, rate of return and the change in asset prices, if such data exist.

It is argued that a capital consumption measure does not capture the productive capacity of the asset, or measure capacity utilisation. On the contrary, it is argued that the interest on the cost of the purchase is productive, given that it is the cost of foregoing intermediate consumption.

\section{Defence capital in the National} Accounts

Military defence capital is currently included in the National Accounts as a capital consumption estimate. This traditional approach uses the ONS PIM to measure gross investment (new assets acquired), and the price of that new investment, while making some assumptions about how the quantity and value of older assets change over time - arithmetical depreciation.

The problems with the current measure are:

- capital consumption does not measure the services rendered from the capital stock

- the PIM estimates capital consumption using outdated data on depreciation rates which are not defence specific, and

- the current method excludes durable destructive military equipment such as submarines and tanks. This has been discussed in Box 1

The current method can be improved, using data available from DASA, HM Treasury (HMT) and ONS as follows:

- the capital consumption measure could be improved by including durable destructive military equipment and by using data more specific to defence, and

- a capital services method can be pursued if assets lives and estimates of rental rates could be modelled from DASA data. Asset prices could be observed using market transactions

\section{Inputs summary}

Figure 2 shows the volume of labour, goods and services, and capital inputs used as a proxy for defence output in the National Accounts.

Defence output as currently measured in the National Accounts has grown by an annual average of 1.4 per cent between 1996

Figure 2

Volume of defence labour, goods and services and capital inputs

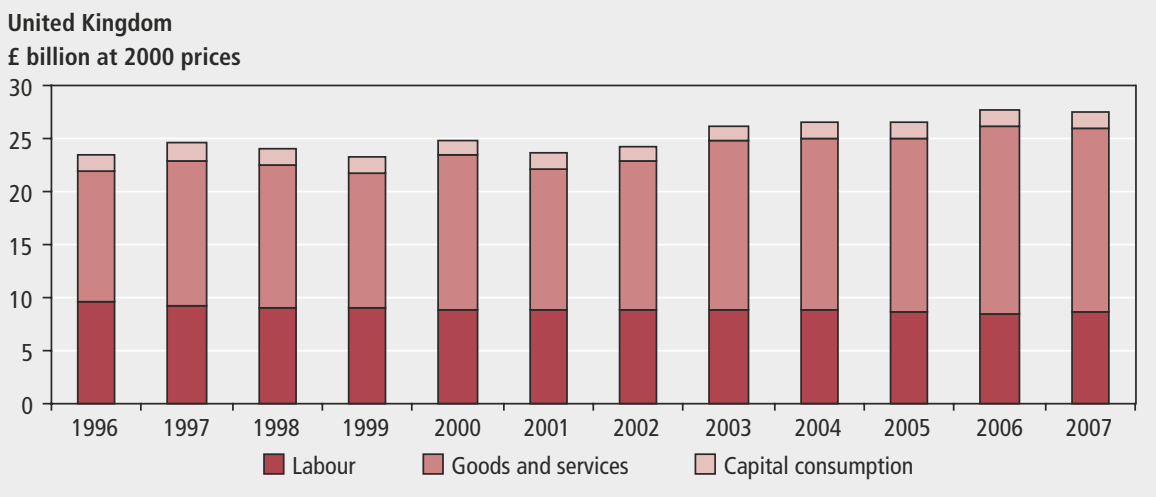

Source: Office for National Statistics

and 2007. It is not yet possible to say how this measure might change if the proposed improvements are made.

\section{Measuring defence output}

Defence output in the National Accounts is measured using the output = input convention, where the volume of output is equal to the volume of input. While this is acceptable by international standards, this does not preclude work to attempt to measure outputs separately.

A direct output measure would make it possible to analyse productivity change and 'there is an intrinsic case based on public accountability for seeking to measure what is achieved by spending on public services' (Atkinson 2005).

Measuring output directly would also be beneficial for stakeholders, such as MoD, HMT and the National Audit Office, as it would offer a high level measure of what the British public is getting for money spent on defence services. This is particularly important given the MoD's current position in which it is engaged in two separate, but equally challenging, theatres in Iraq and Afghanistan, while facing major efficiency drives and organisational reforms at home.

\section{What is defence output and how} could it be measured?

In the development of a direct output volume measure, the key conceptual issue that has to be addressed is how to define a 'unit of output.' The aim of the MoD is to 'deliver security for the people of the United Kingdom and the Overseas Territories by defending them, including against terrorism; and to act as a force for good by strengthening international peace and stability' (MoD 2003). It is not easy to define a 'unit of security' or a 'unit of peace and stability'.

Expenditure on defence can be seen to provide multiple benefits, such as peace, security, damage limitation in wartime and pursuit of, and protection of, national interests. But none of these can easily be measured and they would involve measuring the counterfactual (that is, what would happen in the absence of defence services) in order to determine the reduction in risk of an attack or reduction in damage that results from defence services. It could also be argued that increased defence activity has a negative impact on security, for example, 'higher UK defence spending and more British troops allocated to Iraq and Afghanistan might make the UK more likely to be subject to terrorist attacks so reducing its security' (Hartley 2006).

While high level outcomes, such as peace and security, are difficult to measure, there are a number of intermediate steps between inputs and outcome which could be used to measure output. This article considers two possibilities: activities which measure specific things the Armed Forces do, and capabilities of the Armed Forces (the ability of the forces to pursue a particular course of action, such as precision strike of military targets). The defence scoping paper (Anagboso and Spence 2008) discusses a further possibility, namely the extent to which the objectives of the MoD are met.

Figure 3 illustrates the connections between these concepts. Inputs can be seen as leading to activities which in turn lead to capabilities, but inputs can also lead directly to capabilities, for example, through the purchase of more advanced equipment. Capabilities and objectives interact as the extent to which the MoD meets its objectives will be determined by whether it has the capabilities required to meet those objectives. The objectives that are set will therefore determine what capabilities are required. There is also a 


\section{Figure 3}

\section{Relationship between inputs, output and outcomes}

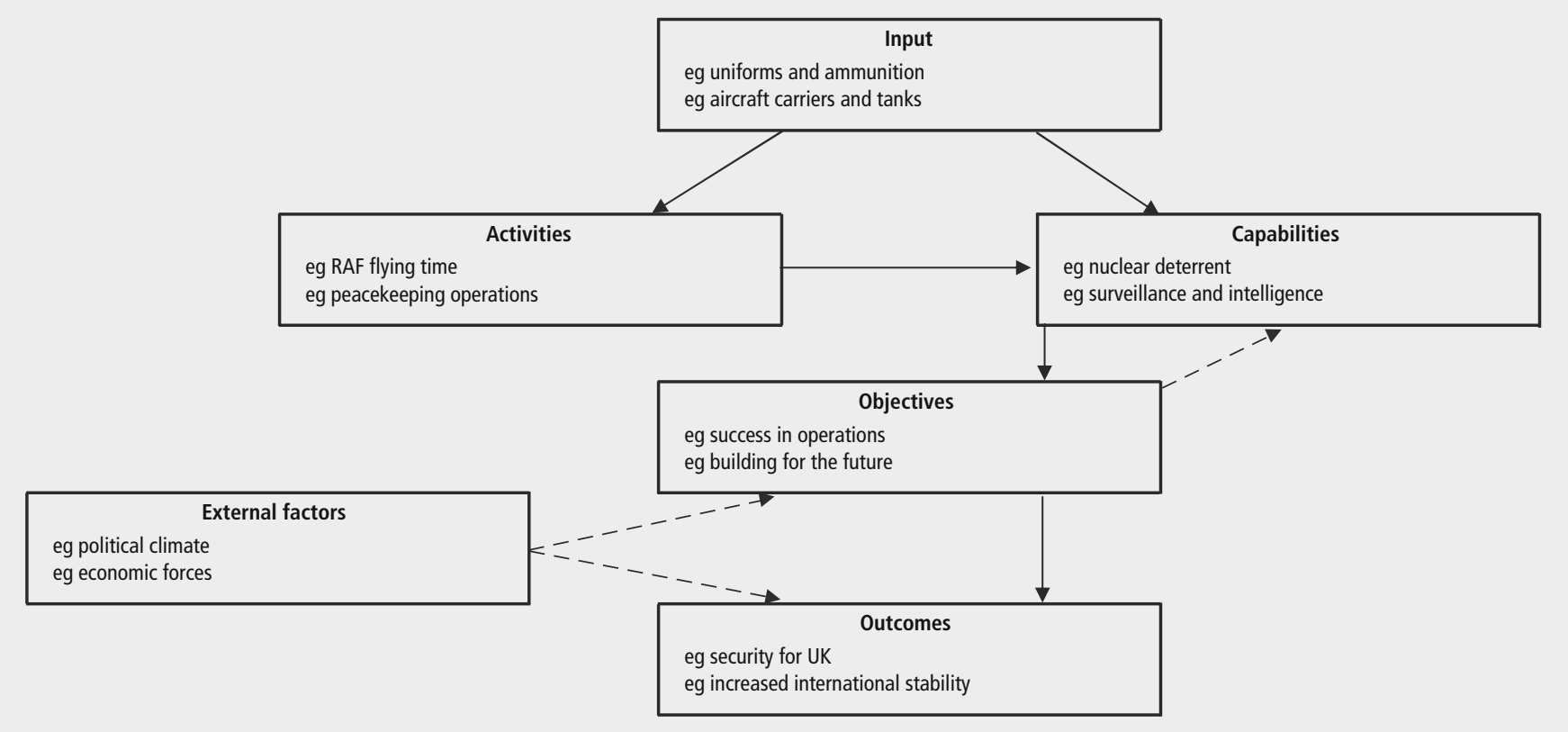

role for external factors, such as political motives, to influence what objectives are set and ultimately what outcomes are achieved.

\section{Activities approach}

Measures of activity reflect what nonmarket units are actually doing with their inputs. In order to apply this approach to defence, a full set of activity measures, with corresponding unit costs, that adequately covers the full range of defence activities needs to be developed. Decisions are needed on whether 'units of output' include areas like training, which are in a sense secondary to active assignments. There are limited data about the numbers and nature of active assignments.

Currently, the only published series is the percentage of service personnel engaged in operations and military tasks from year to year.

As the availability of defence activity data tends to be limited, earlier work in Sweden (Murray 1995) used training data as a proxy for activity data, as this may be more readily available. Murray used hours of attendance at flight training and days of training conscripts, multiplied by unit costs, as output indicators. This follows the argument that 'it is likely that the fighting ability [i.e. the ability of the defence forces to defend the State from any attack that actually materialised] is a positive function of the amount of training completed' (Verikios 1998).

There are certain defence training activities for which measures are readily available in the UK. For example, the RAF can provide data on flying hours (by aircraft type and role), while the Royal Navy can provide data on days spent at sea. For the Army, it may be more difficult to determine an exhaustive list of training activities and measures. However, for a measure of Army training, it may be possible to look at personnel data on gains to trained strength, and data on military exercises in which soldiers undertake 'realistic training' in various aspects of operations. Figure 4 demonstrates the sort of data which are readily available that could be used to create a training/ activity indicator. It shows the number of personnel that have successfully reached trained status within each service each year.

Activity data, where available, could be weighted together with training data, using cost weights, in order to form an aggregate index. However, a cost-weighted activity index which depends largely on information about training activities would primarily measure what service personnel do when they are not engaged in operations. As a result, it is not necessarily a useful measure of final output (except where the amount of training is directly related to force quality). A further limitation to this approach is that it does not capture quality. The assumption is that more training and more people engaged on operations is a greater output. It could be the case that a lower volume of better targeted and higher quality training, or smaller scale operations that are more successful, are a truer reflection of high output. It also fails to measure deterrence, which is an underlying issue in the measurement of defence output.

As a result, an activity index (built up from training data) is unlikely to be a suitable measure of defence output. One approach which shows more promise is a measure of capability.

\section{Figure 4 \\ Gains to trained strength for each service}

United Kingdom

Number of personnel

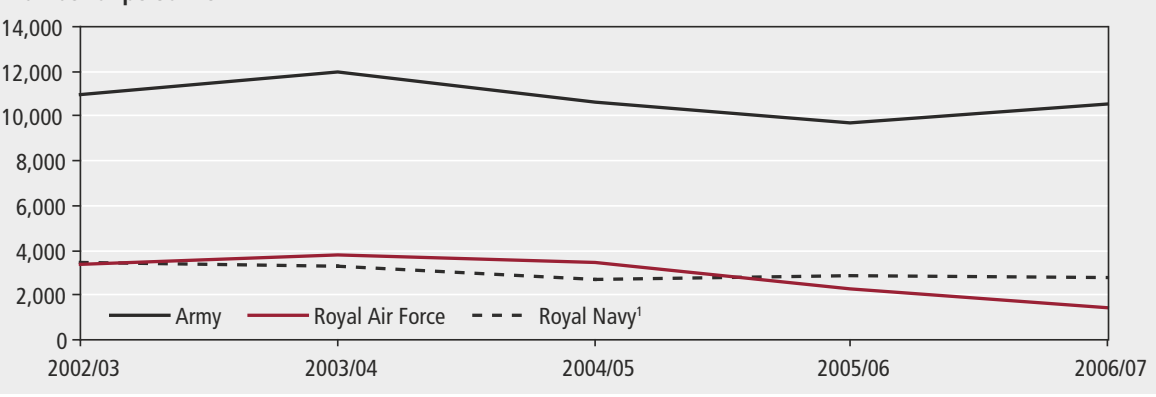

1 Includes Royal Marines. 


\section{Capability approach}

Defence output can be considered to be the sum of the capabilities the Armed Forces provide. Capability describes the ability to execute a specific course of action. The Armed Forces require a range of capabilities, from those that are essential for fighting wars to those needed for peace support and humanitarian operations.

The capabilities required of the Armed Forces at any time are determined by a number of factors, such as the standing commitments and targets or objectives of the $\mathrm{MoD}$, the nature and level of threats to national security and, perhaps more importantly, the capabilities of current or potential adversaries. UK capabilities will also be influenced by membership of NATO and other alliances, to the extent that operations are planned to be undertaken jointly.

During the Cold War, the focus of the Armed Forces was on preparing for, and deterring, a direct military attack on the UK or Western Europe. In the post Cold War era, the security environment has been greatly transformed as there is no longer a direct military threat to the UK or the Overseas Territories. Since the end of the Cold War, the biggest change to the Armed Forces has been the shift of focus from forces deployed in protection of the UK and Western Europe towards deployable and sustainable expeditionary forces with the ability to rapidly acquire and disseminate information, in order to address the challenges of terrorism and the proliferation of Weapons of Mass Destruction.

The Defence White Paper (MoD 2003) identified a number of key capabilities for the UK Armed Forces in the current international security context. This article will discuss capability in terms of the eight key capabilities:

- C4ISR/NEC - command, control, communications, computers, intelligence, surveillance and reconnaissance (C4ISR) and the linked concept of network enabled capability (NEC) refer to the enabling activities that provide knowledge at all levels of operations and enable the planning, organisation and efficient execution of contingencies through effective linkage of platforms

- logistics - this includes the timely provision of assets (such as ammunition) to personnel in the field and the provision of medical support in the field

- Special Forces - these are a vital element of counter-terrorism and intelligence gathering work. They are sometimes referred to as 'force multipliers' - a recognition that small teams of Special Forces can achieve results comparable with much larger forces

- nuclear deterrent - the White Paper identified that 'the continuing risk from the proliferation of nuclear weapons, and the certainty that a number of other countries will retain substantial nuclear arsenals, mean that our minimum nuclear deterrent capability, currently represented by Trident, is likely to remain a necessary element of our security'

- strategic lift - in the post-Cold War era, the trend has been towards force projection operations for which the Armed Forces need to deploy rapidly across the globe. This sort of operation places an increasing premium on transport and lift capabilities

- maritime - the current emphasis in the maritime environment is on delivering effect from the sea onto land. This, to a large extent, comes under the strategic lift capability; however, maritime forces are also required to protect carriers and deployed forces and to ensure continued access to the theatre. Maritime forces also play a role in humanitarian and disaster relief operations, for example, by evacuating citizens

- land - land forces might be used on any of a full range of tasks, from peace support to high intensity fighting. Key requirements for these forces are firepower, with greater emphasis on precision and range, protection for UK forces and forces that are more deployable and more mobile in theatre, and

- air - air power is a fundamental component of both fighting capability and humanitarian deployments. It can be used in support of maritime warfare, on most battlefields, and provide an offensive capability in its own right. Long-range air attack continues to be important both as an integral part of fighting wars and as a coercive instrument to support political objectives

Figure 5 sets out in more concrete terms some of the elements which affect UK capability in the eight key areas, and which could be used as proxy measures for capability. These are based on the information provided in various $\mathrm{MoD}$ publications.

\section{Measuring capability}

There are two possible measures of capability for each of the eight key capabilities:

- quality-adjusted equipment measure, and

- quality-adjusted manpower measure

For some areas, such as lift and logistics, an equipment measure may be sufficient, as the capabilities depend, to a large extent, on the availability of equipment and advances in technology. For others, such as land, air and maritime, it would be more appropriate to look at a manpower measure or a combination of the two measures, weighted together using cost weights. While it could be argued that capabilities are largely reflected by the level of technological advances in the equipment available to the Armed Forces, recognition has also been made of the fact that 'Ultimately, the delivery of effective operational capability relies on our ability to deploy sufficient numbers of Armed Forces personnel with the right skills and training, supported by civilian personnel' (MoD 2003).

The measures set out below are essentially input measures in the sense that 'they focus on understanding what "goes into" the making of an effective national military capability and how such effectiveness can be compared across countries' (Tellis et al 2000).

The two possible measures of capability would have both a quantity and a quality component. For the equipment measure, data are available on equipment holdings (quantity component). Figure 6 illustrates the sort of data which are available.

Explicit quality adjustment would be carried out to take account of quality changes over time. As technology continues to improve, equipment holdings may be reduced as larger numbers of items are replaced with fewer, higher quality items. For example, lift equipment could be adjusted by capacity, that is, the number of aircraft it can carry or the tonnage it can transport. It would also be important to take readiness into account, since assuming that modern sophisticated equipment is more productive is problematic, as the readiness of equipment is arguably the most important factor.

The quantity component of the manpower measure would be the number of service and civilian personnel, broken 


\section{Figure 5}

\section{Key capabilities and factors of capability level}

\begin{tabular}{|c|}
\hline C4ISR/NEC \\
Sensors - unmanned air vehicles (UAVs) \\
$\quad$ - airborne stand-off surveillance \\
Communication - BOWMAN combat radio \\
$\quad$-Skynet 5 satellite \\
Skills - training in equipment operation \\
- addressing manning 'pinch points' \\
- human intelligence (HUMINT) \\
\end{tabular}

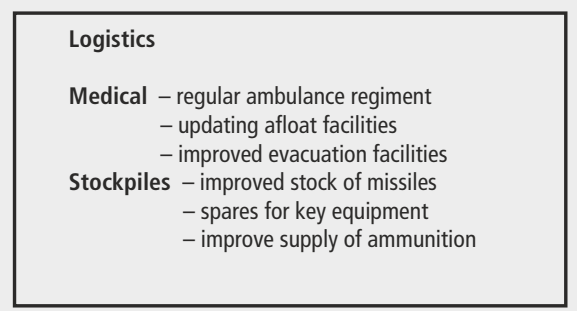

\section{Special Forces}

Special Forces play an important role in rapid deployment of expeditionary forces, but while expenditure is being increased details of enhancements will remain classified.

\begin{tabular}{|c|c|c|c|c|}
\hline \multicolumn{2}{|c|}{$\begin{array}{l}\text { Nuclear deterrent } \\
\text { Nuclear deterrent systems need to be invulnerable and undetectable to } \\
\text { be able to maintain a high state of readiness. For these and other } \\
\text { reasons, the UK maintains a continuous submarine deterrent patrol. } \\
\text { The use of ballistic missiles means that effect can be delivered at greater } \\
\text { range with a larger payload and is harder to intercept. }\end{array}$} & \multicolumn{3}{|c|}{ 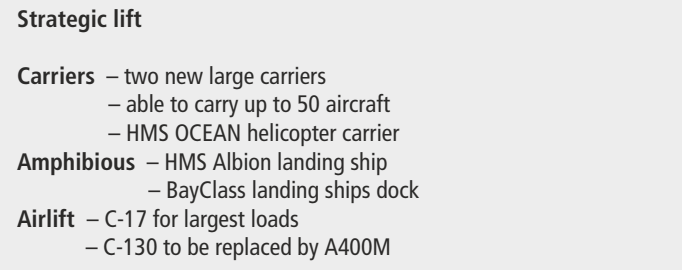 } \\
\hline Maritime & Land & & Air & \\
\hline $\begin{array}{l}\text { Protection } \\
\quad \text { - destroyers } \\
\quad \text { - frigates } \\
\begin{aligned} & \text { Submarines } \text { - ASTUTE class } \\
& \text { - tomahawk missiles } \\
& \text { Humanitarian Relief - evacuation ships }\end{aligned}\end{array}$ & \multicolumn{2}{|c|}{$\begin{array}{l}\text { Mobility - eg tanks and wheeled vehicles } \\
\begin{aligned} & \text { Firepower } \text { - apache attack helicopters } \\
& \text { - light and heavy machine guns } \\
& \text { - mortar systems } \\
& \text { Protection } \text { - armoured personnel vehicles } \\
& \text { - body armour } \\
& \text { - CBRN protection e.g. vaccines } \\
& \text { Balance - light, medium and heavy forces }{ }^{1}\end{aligned}\end{array}$} & $\begin{array}{l}\text { Long-range } \\
\text { Battlefield st } \\
\text { Air-combat }\end{array}$ & $\begin{array}{l}\text { rnado GR4 bomber } \\
\text { orm shadow missile } \\
\text { prt - merlin helicopter } \\
\quad \text { - chinook helicopter } \\
\text { RAAM }{ }^{2} \\
\text { rofighter }\end{array}$ \\
\hline
\end{tabular}

\section{Notes:}

1 Heavy forces have greater firepower and tactical mobility and protection for ground manoeuvres; however, they are much harder to deploy. Light forces provide the UK's rapid deployable capability but lack firepower and protection; medium forces are more deployable than heavy forces but with more mobility and protection than light forces.

2 ASRAAM: advanced short-range air-to-air missiles.

\section{Figure 6}

\section{Count data on Royal Navy ship holdings}

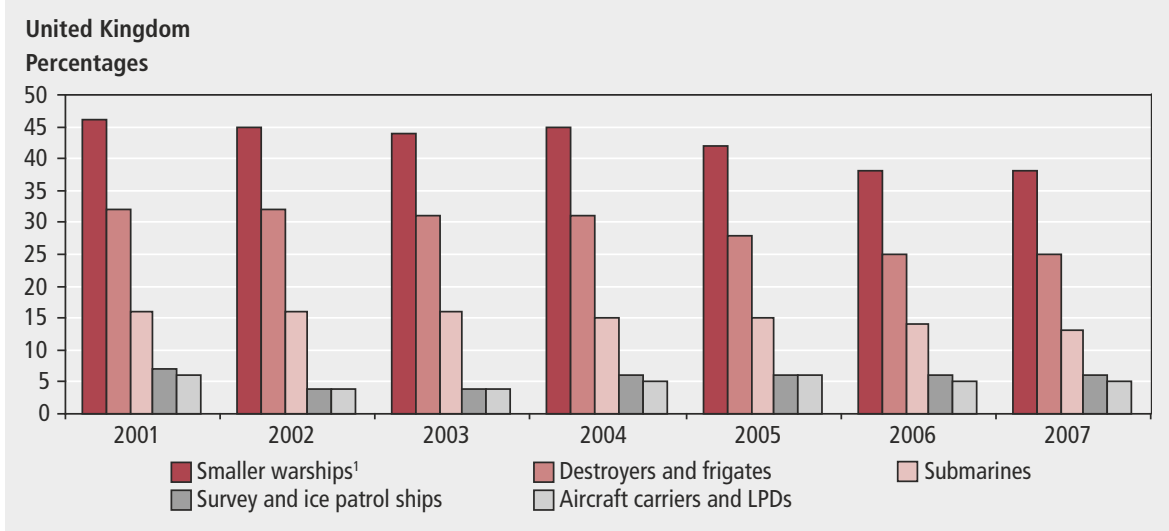

Note:

Source: Defence Analytical Services and Advice (2007)

1 Includes minehunting and offshore patrol vehicles.

down by service and by rank or grade.

Quality adjustments could be based on:

- 'manning balances' that identify whether services have the correct number of staff based on current planning assumptions. The MoD has a target of ensuring trained strength in each service is within +1 and -2 per cent of trained liability. The data available are illustrated in Figure 7

- manning 'pinch points' that identify where there is a deficit in personnel within specialised areas, for example,
RAF pilots. The MoD targets to correct pinch points within services where manning within individual specialisations or ranks is significantly out of balance

- each service also has its own set of guidelines which set out how long service personnel should spend away from their families and the time that units should have between operational deployments (these are known as HARMONY guidelines). For example, Royal Navy and Royal Marines should spend no more than 660 days of separated service over a rolling threeyear period, with Fleet units spending no more than 60 per cent of time deployed in a three-year cycle

- the MoD also reports the percentage of staff that is medically fit for task

These factors, and others such as morale, level of experience (measured as time in uniform), voluntary outflow exits and educational attainment, could be used to create a quality-adjusted measure of 
Figure 7

\section{Armed Forces trained strength as a percentage of required strength for each Service}

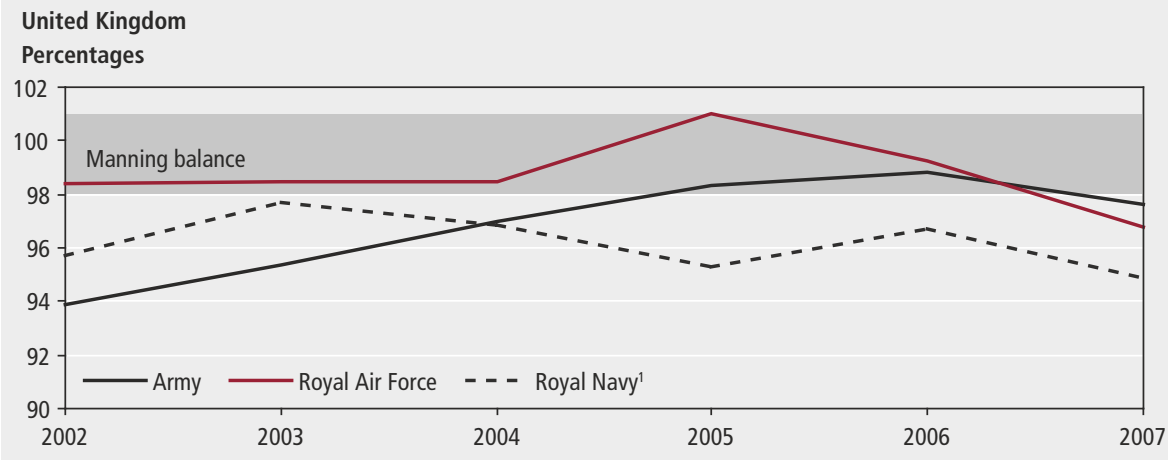

Note:

1 Includes Royal Marines.

capability. The assumption is that when Armed Forces are staffed to the required level, medically fit, trained and suitably rested between tours, their ability to carry out the tasks required of them will be optimal.

The measurement of nuclear deterrent capability may not suit either of these measures as it could be argued that a country either has a nuclear deterrent or does not.

\section{Issues and conclusions}

There are a number of difficulties with using an output measure based on capabilities.

- It would be difficult to obtain an exhaustive list of capabilities and, even when capabilities have been identified, much of the relevant data may be classified due to its sensitive nature. For this reason, an output measure based on capability would require a high degree of aggregation and may not be fully transparent to those outside ONS and MoD

- Consideration is needed on how best to weight together different elements of the capabilities (for example, should aircraft carriers have more weight than amphibious landing craft?) and how to form an aggregate measure across all capabilities (for example, is lift capability more, less, or equally important as nuclear deterrent capability?). While it may be possible to develop cost weights, these may not reflect the value of different capabilities in terms of their impact on peace and security

- The capability of the UK will be influenced by the capabilities of allies where they are working on joint operations

Source: Defence Analytical Services and Advice (2007)
- Capability targets change over time and so it may be difficult to judge whether output has increased, decreased or simply changed over time due to differing targets, and measure should be adjusted down when the capabilities are not actually being used and, if so, how? It could be argued that capabilities could be weighted by their impact on current objectives (though this would be difficult), but it could also be argued that even if they are not being used, capabilities are playing an important role as they act as a deterrent

It would be possible to develop a capability measure as some data are readily available. This approach shows some potential although not all the above issues can be overcome. It would rely on close cooperation between UKCeMGA and MoD as some of the data required are restricted and not suitable for disclosure. Moreover, as this indicator measures absolute capability of the UK Armed Forces, rather than capability relative to other countries, it does not necessarily measure the UK's ability to deliver improvements in peace and security

\section{Conclusion}

This article has examined the current measure of defence output in the National Accounts. Some of the conceptual issues surrounding the measurement of defence output have been discussed. Two direct measures of defence output are proposed in this article - activities and capabilities. A third approach which involves measuring the extent to which $\mathrm{MoD}$ objectives are met is discussed in a separate paper (Anagboso and Spence 2008).

This article provides a basis to help
- Another issue is whether a capability understand the issues surrounding the measurement of defence output. Subject to rigorous assessment by a peer group appraisal body, the proposals put forward to improve the current inputs measures will be adopted in the National Accounts.

\section{ACKNOWLEDGEMENTS}

The authors are grateful for contributions from the Ministry of Defence, Victor Barzey, Professor Derek Leslie and Professor Keith Hartley.

\section{CONTACT}

四elmr@ons.gsi.gov.uk

\section{REFERENCES}

Anagboso M and Spence A (2008) Scoping Paper on Possible Improvements to Measurement of Defence in the UK National Accounts at www.statistics.gov.uk/cci/article. asp?id $=2070$

Defence Analytical Services and Advice (2007) UK Defence Statistics at www.dasa. mod.uk/natstats/ukds/2007/pdf/UKDS2007. $p d f$

Eurostat (2001) Handbook on Price and Volume Measures in the National Accounts.

Kimbugwe K (2008) Capital Inputs in Public Sector Productivity: Methods, Issues and Data at

www.statistics.gov.uk/cci/article. asp?id $=1990$

MoD (2003) Delivering Security in a Changing World: Defence White Paper at www.mod.uk/NR/rdonlyres/051AF3650A97-4550-99C0-4D87D7C95DED/0/ cm60411_whitepaper2003.pdf

MoD (2008) Annual Report and Accounts 2007-2008 Volume I: Annual Performance Report at www.mod.uk/NR/rdonlyres/31D096E9-3F414633-BEA2-AE62CF97C3AE/0/annrptvol1_ 200708.pdf

Murray R (1995) Försvarets kostnader och produktivitet, Stockholm: ESO

Tellis A, Bially J, Layne C, and McPherson M (2000) Measuring National Power in the Post-industrial Age at. http://rand.org/pubs/ monograph_reports/MR1110/MR1110.ch7. pdf

Verikios G (1998) Measuring Output of Government Administration, Defence and Property and Business Services: Some estimates for Australia at www.monash.edu. au/policy/ftp/workpapr/g-127.pdf 


\section{APPENDIX}

\section{Formal definition of National Accounts method of measuring estimates of defence inputs}

Labour

$L D_{v t}=\frac{L D_{2000}}{C_{2000}+S_{2000}} \times\left(C_{t}+S_{t}\right)$

where:

$L D_{v t} \quad=$ Quarterly volume of labour consumption, for military defence activities at time $\mathrm{t}$

$L D_{2000}=$ Quarterly expenditure on labour for military defence activities at year 2000 prices

$C_{t} C_{2000}=$ Number of FTE civilian staff working on military defence activities at time $t$, year 2000

$S_{t}, S_{2000}=$ Number of service personnel working on military defence activities at time $t$, year 2000

Goods and services

$G D_{v t}=\frac{G D_{t}}{\sum_{i=1}^{n} w_{2000 i}{ }^{*} d_{t i}}{ }^{\star} 100$

where:

$G D_{v t} \quad=$ Quarterly volume of intermediate consumption, for military defence activities at time $t$

$G D_{t} \quad=$ Quarterly expenditure on intermediate consumption, for military defence activities at time $\mathrm{t}$

$w_{2000 i}=$ Weight of intermediate consumption in category i used for military defence activities in year 2000

$d_{t i} \quad=$ Deflator for intermediate consumption in category i used for military defence activities in time $t$ 